\title{
Chikungunya outbreak in Montpellier, France, September to October 2014
}

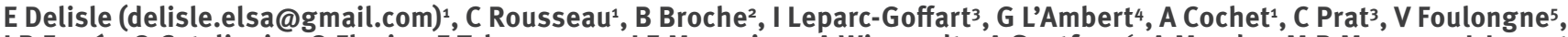
J B Ferré ${ }^{4}, 0$ Catelinois ${ }^{1}$, O Flusin ${ }^{3}$, E Tchernonog 5 , I E Moussion ${ }^{2}$, A Wiegandt $^{2}$, A Septfons ${ }^{6}$, A Mendy M $^{2}$, M B Moyano M L Laporte $^{2}$, J Maurel ${ }^{2}$, F Jourdain 7 , J Reynes ${ }^{5}$, M C Paty $^{7}$, F Golliot $^{1}$

1. Regional office of the French Institute for Public Health Surveillance (Cire Languedoc-Roussillon), Montpellier, France

2. Regional Health Agency of Languedoc-Roussillon, Montpellier, France

3. Institut de Recherche Biomédicale des Armées, National Reference Laboratory for arboviruses, Marseille, France

4. Entente Interdépartementale pour la Démoustication du littoral Méditerranéen (EID Méditerranée), Public mosquito control operator, Montpellier, France

5. Montpellier University Hospital, Montpellier, France

6. French Institute for Public Health Surveillance (Institut de Veille Sanitaire, InVS), Saint-Maurice, France

7. National Centre of Expertise on Vectors, Montpelier, France

Citation style for this article:

Delisle E, Rousseau C, Broche B, Leparc-Goffart I, L'Ambert G, Cochet A, Prat C, Foulongne V, Ferré JB, Catelinois O, Flusin O, Tchernonog E, Moussion IE, Wiegandt A, Septfons A, Mendy A, Moyano MB, Laporte L, Maurel J, Jourdain F, Reynes J, Paty MC, Golliot F. Chikungunya outbreak in Montpellier, France, September to October 2014. Euro Surveill. 2015;20(17):pii=21108. Available online: http://www.eurosurveillance.org/ViewArticle.aspx?Articleld=21108

In October 2014, an outbreak of 12 autochthonous chikungunya cases, 11 confirmed and 1 probable, was detected in a district of Montpellier, a town in the south of France colonised by the vector Aedes albopictus since 2010. A case returning from Cameroon living in the affected district was identified as the primary case. The epidemiological investigations and the repeated vector control treatments performed in the area and around places frequented by cases helped to contain the outbreak. In 2014, the chikungunya and dengue surveillance system in mainland France was challenged by numerous imported cases due to the chikungunya epidemic ongoing in the Caribbean Islands. This first significant outbreak of chikungunya in Europe since the 2007 Italian epidemic, however, was due to an East Central South African (ECSA) strain, imported by a traveller returning from West Africa. Important lessons were learned from this episode, which reminds us that the threat of a chikungunya epidemic in southern Europe is real.

\section{Background}

Chikungunya (CHIK), as well as dengue virus which shares the same vector, has been identified as a threat for mainland France for several years, as all the prerequisites for autochthonous transmission of the virus are present in southern regions $[1,2]$. The mosquito vector, Aedes albopictus, first introduced in southern France in 2004, was established in 18 districts in 2014 [3]; and the virus is regularly introduced by viraemic travellers returning from endemic or epidemic countries to mainland France where the population is naive for chikungunya virus (CHIKV). This situation led to a first episode of autochthonous transmission of chikungunya in south-east France in 2010 [4]. Other countries in the south of Europe are also threatened by CHIK and dengue virus as the vector Ae. albopictus is established in large part around Mediterranean Sea and continues to disseminate further each year. This was demonstrated when an epidemic occurred in Italy in 2007, with more than 200 cases infected in three months [5].

In mainland France, since 2006, a chikungunya and dengue preparedness and contingency plan is implemented every year in vector-colonised districts. This plan aims to prevent the transmission and dissemination of these viruses [3,6]. It describes five risk levels defined according to entomological and epidemiological surveillance results. All clinically-suspected imported cases must be reported to the regional health authority in addition to mandatory notification of confirmed cases. Epidemiological investigations are then implemented as well as appropriate vector control measures in each location visited by patients during their period of viraemia. In addition, a network of laboratories practicing chikungunya and dengue diagnosis provides daily reports of their results to the French Institute of Public Health Surveillance regional boards. This enables identifying imported and autochthonous cases not already notified. A national database collects all suspected and confirmed cases identified during the season.

Here we report the epidemiological and entomological investigations of an outbreak of chikungunya which took place in Montpellier from September to October 2014 and try to explain the reasons why it occurred. Montpellier is a town of 400,000 inhabitants, located on the Mediterranean coast. Ae. Albopictus, identified in 2010, has progressively colonised the whole conurbation. 
The alert

On 1 October 2014, a probable autochthonous chikungunya case was identified in Montpellier (case 1, index case). The patient, a woman in her 40 s living near Montpellier, had developed 13 days earlier, on 18 September, a sudden fever, incapacitating arthralgia, myalgia and a rash. She had not travelled abroad during the two weeks before symptoms onset but had experienced multiple mosquito bites on 14 September in a residential area of Montpellier. She consulted her general practitioner (GP) who prescribed several serological tests, including for CHIKV. Analyses performed on a serum sample taken five days after symptoms onset identified IgM antibodies to CHIKV, that were confirmed by the National Reference Centre (NRC) in Marseille, on 13 October. Real-time reverse transcription PCR (RT-PCR) was negative for this sample.

While waiting for a second blood-sample to confirm the CHIKV infection by seroconversion, four additional suspected autochthonous chikungunya cases were notified on 16 October by the Infectious and Tropical Diseases Department of Montpellier University Hospital (UH) to the regional health authority. These cases (Cases 2 to 5) were adults from a same family and had not travelled abroad recently. They were not linked to the index case. They successively developed acute fever, painful joints and a rash between 20 September and 12 October (Figure).

They lived in a house located ca $150 \mathrm{~m}$ from the place where Case 1 (index case) experienced mosquito bites. On 17 October, a chikungunya real-time RT-PCR was positive for one of the family members at the Montpellier UH virology laboratory. The diagnosis of chikungunya was confirmed for all the family cases and Case 1 by the NRC, respectively on the 20 October and the 22 October (real-time RT-PCR and seroconversion, Table 1).

These geographically and temporally linked cases formed a cluster in a distinct area of Montpellier. According to the national contingency plan against the spread of CHIK and dengue viruses, these findings prompted immediate epidemiological and entomological investigations in order to contain the transmission.

\section{Methods}

\section{Case definitions}

For the investigation, the following case definition was applied. From 1 September to 30 November 2014, in Montpellier and conurbation:

- An autochthonous suspected case of chikungunya was defined by sudden onset of fever $\left(\geq 38.5^{\circ} \mathrm{C}\right)$ and arthralgia, not explained by another medical condition in a person without a history of foreign travel within 15 days prior to symptoms onset.

- An autochthonous probable case was defined as a suspected case with an epidemiological link to a confirmed case or a suspected case with positive chikungunya tests (real-time RT-PCR or serology) performed by a private laboratory, or hospital laboratory.

- An autochthonous confirmed case was defined as a suspected case with positive laboratory tests (real-time RT-PCR or serology positive for IgM and IgG antibodies to CHIKV) performed by the NRC or a suspected case with an epidemiological link to a confirmed case and a serology positive for IgM antibodies to CHIKV performed by the NRC.

\section{Epidemiological investigations}

Immediately after the identification of Case 1 (index case), the enhanced surveillance database was analysed to identify a potential primary case. Among all the imported chikungunya cases identified during the 2014 season, cases that had symptoms onset after 28 July and lived near or visited the same places as Case 1 were listed.

The time after 28 July was considered as the maximal period for viral transmission from symptoms onset of the primary case to symptoms onset of the second case, considering a mosquito lifespan of maximum one month, human incubation of maximum 12 days and human viraemia of seven days.

Active case finding of suspected autochthonous cases was implemented in Montpellier and conurbation: (i) a door-to-door investigation was conducted in the neighbourhood of the autochthonous cases' residences (200m radius). Nearly 1,000 households were targeted, representing ca 2,250 inhabitants; (ii) information on the event and a request to immediately notify all suspected autochthonous cases to the regional health authority was sent to all GPs and laboratories established in the Montpellier conurbation as well as all six emergency medical services (including the Montpellier UH). In addition, health professionals established within a $2 \mathrm{~km}$ radius of the cases' residences were contacted by telephone (30 GPs and 11 laboratories).

For each new suspected case identified, blood samples were collected and analysed by the NRC. Real-time RT-PCR was performed on samples collected within eight days after symptoms onset and serology on samples collected after day 5 of symptoms onset.

\section{Entomological investigations}

Entomological investigations were carried out inside the primary case's property, as soon as this case was identified, and in the affected area, in order to estimate vector densities, using BG Sentinel adult mosquito traps. Prospection of mosquito breeding sites was conducted concomitantly to the door-to-door case finding. 
Timeline of symptoms onset for imported and autochthonous cases of chikungunya and epidemiological features, Montpellier, France, September-October 2014 ( $\mathrm{n}=13)$



Primary case

Confirmed autochthonous case

Probable autochthonous case

Family case

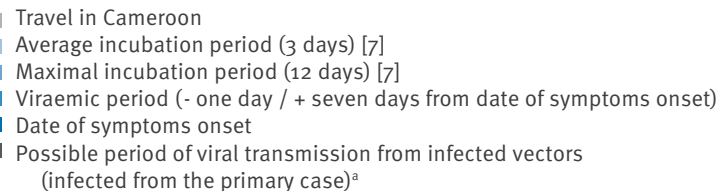

NRC: National Reference Center; RT-PCR: reverse transcriptase-PCR; UH: University Hospital.

Cases numbered by order of identification.

Source : French Institute for Public Health Surveillance (Institut de veille sanitaire), 2014.

a Possible period of viral transmission from infected vector (infected from the primary case):- mosquitoes biting the primary case between the first day and the last day of his viraemic period, extrinsic incubation period: seven days [8], mosquito lifespan: 10 days [9].

\section{Results}

\section{Epidemiological investigations}

\section{Primary case}

An imported case living in the same area as the five autochthonous cases was identified in the enhanced surveillance database. The patient, who had returned from Cameroon on 29 August, had symptoms onset two days later. He consulted at the Montpellier UH and was diagnosed on 5 September by the laboratory of virology via chikungunya-specific real-time RT-PCR on a serum sample at day 3 post symptoms onset (Figure, Table 1). He was immediately notified to the regional health authority. Entomological investigators, responsible for interventions at that time, could not enter his property and did not identify the vector in the vicinity of the case's residence. No mosquito-control treatment was performed then.

Autochthonous cases

The door-to-door case finding and notification by health professionals of suspected autochthonous cases enabled the detection of 20 autochthonous suspected cases of chikungunya in the neighbourhood of Cases 1 to 5 (200m radius). Six cases were laboratoryconfirmed by the NRC (Table 1) and the results were negative for 14 . All six confirmed cases had been identified through the door-to-door investigations. At the time of investigation, five had fully recovered and for sixth case, the symptoms started on the very day of the investigation (Figure). Moreover, epidemiological 
Laboratory investigation of imported and autochthonous cases of chikungunya by the National Reference Centre,

Montpellier, France, September-October $2014(\mathrm{n}=13)$

\begin{tabular}{|c|c|c|c|c|c|}
\hline \multirow{2}{*}{ Case number } & \multirow{2}{*}{$\begin{array}{c}\text { Date of } \\
\text { symptoms onset }\end{array}$} & \multirow{2}{*}{ Date of sampling ${ }^{a}$} & \multicolumn{2}{|c|}{ Serological tests for chikungunya } & \multirow{2}{*}{$\begin{array}{c}\text { Chikungunya real-time } \\
\text { RT- PCR }\end{array}$} \\
\hline & & & $\lg M$ & $\lg G$ & \\
\hline Imported ${ }^{b}$ & 30 Aug 2014 & $D_{3}$ & \multicolumn{2}{|c|}{ ND } & Positive \\
\hline \multirow{2}{*}{$1^{\mathrm{c}}$} & \multirow{2}{*}{18 Sep 2014} & $\mathrm{D}_{5}$ & Positive & Negative & Negative \\
\hline & & D29 & Positive & Positive & ND \\
\hline 2 & 20 Sep 2014 & D28 & Positive & Positive & ND \\
\hline 3 & 24 Sep 2014 & D24 & Positive & Positive & ND \\
\hline 4 & 09 Oct 2014 & $\mathrm{D}_{7}$ & Positive & Positive & Negative \\
\hline 5 & 12 Oct 2014 & D4 & \multicolumn{2}{|c|}{ ND } & Positive \\
\hline 6 & o8 Sep 2014 & D4 & \multicolumn{2}{|c|}{ ND } & Positive \\
\hline 7 & 14 Sep 2014 & $D_{51}$ & Positive & Positive & ND \\
\hline 8 & 14 Sep 2014 & $D_{51}$ & Positive & Positive & ND \\
\hline 9 & 16 Sep 2014 & D6 & Positive & Negative & Negative \\
\hline \multirow{2}{*}{10} & \multirow{2}{*}{11 Oct 2014} & $D_{5}$ & Positive & Negative & Negative \\
\hline & & D23 & Positive & Positive & ND \\
\hline 11 & 22 Oct 2014 & Do & \multicolumn{2}{|c|}{ ND } & Positive \\
\hline 12 & 20 Sep 2014 & ND & \multicolumn{2}{|c|}{ ND } & ND \\
\hline
\end{tabular}

ND: not done; RT-PCR: reverse transcriptase-PCR.

a Day post symptom onset.

b Primary case.

c Index case.

investigations conducted among the family cases (cases 2 to 5 ) identified an additional family member as a probable case, but this patient did not consent to being tested.

Altogether, 12 autochthonous chikungunya cases were identified: 11 confirmed and one probable. For three confirmed cases, the CHIKV was detected (real-time RT-PCR positive) and for eight, IgM with or without IgG antibodies against CHIKV were detected (Table 1). The CHIKV sequence data obtained from sera of two autochthonous cases indicated that the CHIKV infection was due to a strain belonging to the East Central South African (ECSA) genotype harbouring the E1-A226V adaptive mutation (data not shown). Sequencing performed from the primary case serum showed same results.

All cases lived in or had visited the same area of Montpellier, a square of side $250 \mathrm{~m}$ enclosing small buildings and individual houses with many gardens. The median age was 59 years (range 22-80). Half of the cases (6/12) were women. The date of symptoms onset ranged from 8 September 2014 to 22 October 2014. All cases presented with fever and incapacitating arthralgia, mainly in the hands or feet. A rash was present for 10/12 (Table 2), which appeared mainly after fever onset (median two days; range $0-5$ ). Nine of the 12 cases were free of general symptoms (fever, rash, myalgia etc.) within eight days (range 4-21) but seven cases still suffered from persistent joint pains two months after symptoms onset. All cases consulted their GPs while symptomatic but chikungunya diagnosis was suspected only for one (Case 1 , index case). Five were referred to the Montpellier UH where the diagnosis was suspected for four of them (Cases 2 to 5) and laboratory tests carried out.

\section{Entomological investigation and control measures}

Following the identification of Case 1 (index case) and immediately after the primary case had been identified, entomological investigations were repeated in mid-October in the neighbourhood of the primary case residence. They showed very high densities of Aedes albopictus larvae and adults (average of 30 mosquitoes per BG-Sentinel trap per day), promoted by numerous gardens located in the area providing mosquito breeding and resting sites.

A mosquito-control treatment was therefore performed three days later (Figure) in the outbreak area $( \pm 150 \mathrm{~m}$ radius circle around the residences of the primary case, of the family cases and the place visited by case 1), with Ultra Low Volume spraying of deltamethrin (Cerathrin and Aqua-KOthrine 2 and $1 \mathrm{~g}$ of active substance.ha ${ }^{-1}$, respectively). This operation was repeated twice, five days and 11 days later, within a larger area ( $\pm 250 \mathrm{~m}$ radius circle around the case's residences), with consideration to sensitive persons and activities as well as respective institutions in the vicinity such as nursery, kindergarten, elementary and high schools. Following the first insecticide treatment, the vector population declined drastically in the area: from 243 


\section{TABLE 2}

Distribution of symptoms among autochthonous cases of chikungunya, Montpellier, France, September-October $2014(\mathrm{n}=12)$

\begin{tabular}{|l|c|}
\hline Symptoms & Number of cases \\
\hline Fever $>38.5^{\circ} \mathrm{C}$ & 12 \\
\hline Arthralgia & 12 \\
\hline feet / ankles & 10 \\
\hline hands / wrists & 9 \\
\hline Rash & 10 \\
\hline Myalgia & 7 \\
\hline Diarrhoea & 3 \\
\hline Headache & 2 \\
\hline Back pain & 1 \\
\hline
\end{tabular}

Ae. albopictus collected per day with 8 BG Sentinel traps $24 \mathrm{~h}$ before the treatment to eight per day after the treatment. Mosquito-control treatment was also performed around places $( \pm 150 \mathrm{~m}$ radius circle) frequented by each case during viraemia.

The numerous mosquito breeding sites identified in the neighbourhood houses during the door-todoor inspection were eliminated by the Entente Interdépartementale pour la Démoustication (EID) vector control professionals, involving each inhabitant for pedagogical purposes.

Before the fogging of insecticide, an information leaflet was distributed in all mail-boxes inside the treatment area, concerning the epidemiological situation, the aim of the treatment and with explanation how to limit contact with insecticides, and giving recommendations about community mosquito control and protection i.e. maintaining gardens regularly and drying containers filled with water, using repellent, wearing long-sleeved clothes, etc.

\section{Discussion}

This outbreak involving 12 autochthonous chikungunya cases is the first significant outbreak in Europe since the 2007 epidemic in Emilia Romagna, Italy [5]. It started as all the conditions for autochthonous transmission of CHIKV were met in a densely populated neighbourhood of Montpellier with high densities of Aedes albopictus.

The absence of immediate vector control treatment around the primary case's residence where the vector was initially not identified, and the delay in identifying the first autochthonous cases enabled the establishment of a CHIKV transmission cycle, which involves several generations of mosquitoes (incubation 2-12 days [7], extrinsic incubation period 4-13 days [8], mosquito lifespan 10-30 days [9]). This delay is due to the fact that chikungunya is rare in mainland France and except for case 1, none of the GPs consulted by cases suspected the disease.

However, there was a prompt response following the alert. The epidemiological investigations and the repeated vector control treatments performed in the area and around places frequented by cases helped to contain the outbreak: the number of cases was probably curtailed and no spread beyond the affected area was identified. Only one case (case 11) presented with an onset of symptoms three days after the first treatment in the area. The effectiveness of vector control measures was also suggested by the results of trapping before and after treatments. The beginning of autumn and weather conditions in October might also have contributed to the end of the outbreak: the cooler temperatures were unfavourable to virus transmission and vector activity, the shorter daylight period induced egg diapauses and a decrease in vector density. In this outbreak involving a few cases, no socioeconomic factor was identified as favouring the transmission.

The outbreak occurred as the ongoing chikungunya epidemic in the Caribbean Islands [10] alerted the French public health authorities and challenged the national surveillance system $[3,11,12]$. Four hundred and five of the 449 (90\%) imported cases of chikungunya identified during the 2014 season in the French vector-colonised districts were returning from the French West Indies, where the Asian genotype of CHIKV circulates [13]. No autochthonous transmission had been identified from those imported cases. The primary case in the outbreak, however, was a viraemic traveller returning from Cameroon, infected by a strain belonging to the ECSA genotype with the E1-A226V adaptive mutation. These observations raise questions about the adaptation of the Asian genotype CHIKV strain circulating in the Caribbean to Aedes albopictus [14].

This outbreak, like the previous autochthonous cases of chikungunya and dengue which occurred in southern France since 2010 [4,15-17], highlights that autochthonous transmission of vector-borne diseases is possible and can lead to outbreaks in France, under favourable climatic and entomological conditions. Repeated episodes of transmission of chikungunya or dengue viruses are likely to occur in the future, especially as the vector is spreading further each year: in 2014, in France, more than 14 million residents live in areas colonised by Aedes albopictus, including many densely-populated cities.

This episode, detected and contained early when the number of cases was still limited, shows the importance of the French contingency plan, whose purpose is, more than to avoid autochthonous transmission, to contain them. The plan organises epidemiological and entomological surveillances, facilitates the coordination of investigations and mosquito control activities, allows the anticipation of necessary resources in case of an outbreak and provides regulatory tools. This plan is evaluated and adapted every year in order to 
maintain its efficiency. However, the involvement of the population and health professionals is a key point for success. Thus, given the observations stated during the investigations, the following actions need to be pursued in the French vector- colonised areas to improve public health response: (i) increasing population awareness regarding the risk of chikungunya and dengue and consequently improving prevention (from individual protection to breeding sites control) in order to limit vector-borne transmission; (ii) increasing awareness of physicians and laboratories regarding the possibility of autochthonous transmission, the appropriate laboratory diagnosis tools and the notification of cases; (iii) maintaining a coordinated approach and a close collaboration between epidemiological and entomological surveillance, as well as a concerted preparedness of the various parties such as national and local health authorities, vector control professionals, national laboratory before the start of the season in order to facilitate rapid response.

\section{Conclusion}

This outbreak, following importation of an ECSA CHIKV strain by a traveller returning from Cameroon, is the first significant one in mainland France. Such a local circulation of the virus was not unexpected and the national contingency plan showed its effectiveness in controlling the outbreak. However, some weaknesses, in vector control measures around the primary case and awareness of health professionals, facilitated the spread of the virus. Contingency plan and epidemiological and entomological surveillance stakeholder preparedness is necessary to implement rapid and proportionate measures of surveillance and control. Awareness of health professionals and the community about vector control and disease symptoms need to be strengthened.

\section{Acknowledgements}

The biomedical laboratories Cerba (Saint-Ouen l'Aumone) and Biomnis (Lyon). The private laboratories and the general practitioners of the Hérault district; C Ricoux, InVS, France and S Guglielmi, C Salvio, S Lesterle, O Puech, ARS, France and C Tizon, J Vidal, T Perimentel, F Richard, L Vançon, S Estaran EID Méditerranée, France for contributing to the field epidemiological investigations; vector control professionals at EID Méditerranée; D Bouillin and F Entezam, ARS, France; E Couturier and H De Valk, InVS, France, for reviewing the manuscript. The patients and their relatives approached for this investigation.

\section{Conflict of interest}

None declared.

\section{Authors' contributions}

Contribution to the epidemiological investigations: $\mathrm{E}$ Delisle, C Rousseau, MC Paty, A Cochet, O Catelinois, F Golliot, A Septfons, A Mendy, MB Moyano, L Laporte, J Maurel. Interviews of the patients: A Mendy, MB Moyano, L Laporte, J Maurel, E Delisle. Diagnosis of the family cases and notification to health authorities: E Tchernonog, J Reynes, V Foulogne. Implementation of the control measures: B Broche. A Wiegandt, I Estève-Moussion. Coordination of the control measures: $B$ Broche. Entomological investigations and coordination of vector control treatment: G L'Ambert, JB Ferré. Laboratory investigations: I Leparc-Goffart, C Prat, O Flusin. Coordination of the epidemiological investigations: E Delisle, C Rousseau (regional level), MC Paty (national level). Supervisor of the investigations: F Golliot. Drafted the manuscript: E Delisle, C Rousseau, MC Paty. Contribution to the writing of the paper: A Cochet, $O$ Catelinois, $G$ L’Ambert, F Jourdain, I Leparc-Goffart, A Wiegandt.

\section{References}

1. Fontenille D, Failloux AB, Romi R. Should we expect Chik and dengue in southern Europe? In: Takken W, Knols BGJ, editors. Emerging pests and vector-borne diseases in Europe. Vol 1. Wageningen Academic Publishers;2007.

2. Tomasello D, Schlagenhauf P. Chikungunya and dengue autochthonous cases in Europe, 2007-2012. Travel Med Infect Dis 2013;11(5):274-84.http://dx.doi.org/10.1016/j.tmaid.2013.07.006 PMID:23962447

3. Paty MC, Six C, Charlet F, Heuzé G, Cochet A, Wiegandt A, et al. Large number of imported chikungunya cases in mainland France, 2014: a challenge for surveillance and response. Euro Surveill. 2014;19(28):20856. http://dx.doi.org/10.2807/1560-7917. ES2014.19.28.20856 PMID:25060572

4. Grandadam $M$, Caro V, Plumet $S$, Thiberge JM, Souarès $Y$, Failloux $A B$, et al. Chikungunya virus, southeastern France. Emerg Infect Dis. 2011;17(5):910-3.http://dx.doi.org/10.3201/eid1705.101873 PMID:21529410

5. Rezza G, Nicoletti L, Angelini R, Romi R, Finarelli AC, Panning M, et al.; CHIKV study group. Infection with chikungunya virus in Italy: an outbreak in a temperate region. Lancet. 2007;370(9602):1840-6 http://dx.doi.org/10.1016/S0140-6736(07)61779-6 PMID:18061059

6. Ministère des Affaires Sociales et de la Santé. Guide relatif aux modalités de mise en œuvre du plan anti-dissémination du chikungunya et de la dengue en métropole. [Chikungunya and dengue preparedness and response plan to monitor and prevent dengue preparedness and response plan to monitor and prevent des Affaires Sociales et de la Santé; 2014. French. [Accessed 11 November 2014]. Available from: http://circulaire.legifrance.gouv.fr/ pdf/2014/05/cir_38279.pdf

7. Burt FJ, Rolph MS, Rulli NE, Mahalingam S, Heise MT. Chikungunya: a re-emerging virus. Lancet. 2012;379(9816):662-71.http://dx.doi. org/10.1016/S0140-6736(11)60281-X PMID:22100854

8. Christofferson RC, Chisenhall DM, Wearing HJ, Mores CN. Chikungunya viral fitness measures within the vector and subsequent transmission potential. PLoS ONE. 2014;9(10):e110538. http://dx.doi.org/10.1371/journal.pone.0110538 PMID:25310016

9. Hawley WA. The biology of Aedes albopictus. J Am Mosq Control Assoc Suppl. 1988;1(suppl):1-39. PMID:3068349

10. Ledrans M, Cassadou S, Boucau S, Huc-Anaïs P, Leparc-Goffart I, Prat $C$, et al. Émergence du chikungunya dans les départements français d’Amérique: organisation et résultats de la surveillance épidémiologique, avril 2014. [Emergence of chikungunya in the French overseas territories of the Americas: organization and results of epidemiological surveillance, April 2014]. Bull Epidémiol Hebd (Paris). 2014;(21-22):368-79. French. Available from: http:// www.invs.sante.fr/beh/2014/21-22/2014_21-22_1.html

11. European Centre for Disease Prevention and Control (ECDC). Chikungunya outbreak in Caribbean region. Stockholm: ECDC 2014 June. Available from: http://ecdc.europa.eu/en/publications/ Publications/chikungunya-caribbean-june-2014-risk-assessment.pdf

12. Noël H, Rizzo C. Spread of chikungunya from the Caribbean to mainland Central and South America: a greater risk of spillover in Europe? Euro Surveill. 2014;19(28):20855. http://dx.doi. org/10.2807/1560-7917.ES2014.19.28.20855 PMID:25060570

13. Leparc-Goffart I, Nougairede A, Cassadou S, Prat C, de Lamballerie X. Chikungunya in the Americas. Lancet. 2014:383(9916):514.http:// dx.doi.org/10.1016/S0140-6736(14)60185-9 PMID:24506907

14. Weaver SC. Arrival of chikungunya virus in the new world: prospects for spread and impact on public health. PLoS Negl Trop Dis. 2014;8(6):e2921. http://dx.doi.org/10.1371/journal.pntd.0002921 PMID:24967777

15. La Ruche G, Souarès $Y$, Armengaud A, Peloux-Petiot F, Delaunay $P$, Desprès $P$, et al. First two autochthonous dengue virus infections in metropolitan France, September 2010. Euro Surveill. 2010;15(39):pii=:19676.

16. Marchand E, Prat C, Jeannin C, Lafont E, Bergmann T, Flusin O, et al. Autochthonous case of dengue in France, October 2013. Euro Surveill. 2013;18(50):20661.http://dx.doi.org/10.2807/1560-7917. ES2013.18.50.20661 PMID:24342514

17. Giron S, Rizzi J, Leparc-Goffart I, Septfons A, Tine R, Cadiou B, et al. Nouvelles apparitions de cas autochtones de dengue en région Provence-Alpes-Côte d'Azur, France, août-septembre 2014. [New occurrence of autochthonous cases of dengue fever in southeast France, August-September 2014]. Bull Epidemiol Hebd (Paris). 2015; (13-14):217-23. Available from: http://www.invs.sante.fr/ beh/2015/13-14/2015 13-14 3.html 